\title{
Bridging the Knowledge Gap for African Researchers through Open Access Publishing: The Case of African Higher Education Research Online (AHERO)
}

\author{
Beatrice Sekabembe ${ }^{1}$ and Jude Ssempebwa ${ }^{2}$ \\ ${ }^{1}$ East African Institute of Higher Education Studies and Development, Makerere University. \\ P.O. Box 7062 Kampala, Uganda \\ bsekabembe@educ.mak.ac.ug \\ ${ }^{2}$ Research Directorate, Uganda Martyrs University. P.O. Box 5498 Kampala, Uganda \\ jude_ssempebwa@yahoo.co.uk
}

\begin{abstract}
This paper reports on African Higher Education Research Online (AHERO), an innovative web based open access project that facilitates the communication of research on African higher education that is otherwise invisible. In addition, the paper demonstrates the functionality of the AHERO website, to show how and why authors may deposit their papers; and provides a report of the methods used to populate the archive, how AHERO deals with copyright and the progress that has been made thus far. Some experiences are shared. It ends with the conclusions and recommendations drawn from an assessment survey.
\end{abstract}

Keywords: Digital libraries; e-resources; digital repository.

\section{Introduction}

The need for research, to inform development endeavors in the developing world, cannot be over emphasized, since knowledge is a key ingredient in the pursuit of sustainable development. Nonetheless, researchers need adequate access to information resources that are relevant to their work and to publication outlets if they are to make a meaningful contribution in the area of research. Since a significant body of literature is locked behind copyright licenses and exorbitant journal subscription fees, however, in Africa, many researchers do not have adequate, let alone convenient, access to many of these information resources. Besides, many journals are membership based and levy membership and publication fees that many African researchers cannot easily afford. Resultantly, information flows to and from African academics are blocked by the intellectual hegemony and gate-keeping practices of the journals that have good visibility, usually based in Europe and North America. Moreover, poor bibliographic control and weak dissemination systems curtail the circulation of the few publications by African researchers. Nevertheless, the departure from the traditional mode of publishing to an open access mode (through which researchers can publish, disseminate and access research free of direct cost) is seen as presenting an opportunity for overcoming these challenges. 


\subsection{The Problem - Scarcity and Invisibility of Knowledge in Africa}

Knowledge scarcity: As part of their three track mandate, academics in Africa are expected to generate and disseminate new knowledge. To live up to this expectation, however, these academics need convenient access to information resources, to inform their research efforts; and publication outlets, to disseminate their findings. Over the last three decades, however, many African academics have found it difficult to access quality information resources, because, for a host of reasons, many libraries, and academics, are unable to procure quality information resources. Consequently, the academics ignore the research dimension of their job; or do it albeit improperly, often with significant duplication of efforts. Incidentally, the tendency not to undertake research, and to produce poor quality manuscripts, compounds the shortage of the information resources that are available to academics in Africa, since poor quality manuscripts are commonly rejected by the more visible publication outlets. Already, for example, Altbach (2007) and Mohamed (2009) have decried that academics in Africa do not have access to both information materials and publication outlets. Unfortunately, even in cases where the academics are able to do some research, little gets to be known about the research beyond the settings in which it is carried out, since it is usually published in journals that have limited international, and national, distribution. This could discourage researchers, since they do not receive feedback from their colleagues. Even in the few instances where academics in Africa are able to publish in the more widely disseminated journals, their colleagues on the continent are kept away from these works, since the works are locked behind exorbitant licence fees.

Knowledge is a major resource for development. In universities worldwide, knowledge forms the basis of their missions of teaching, research and community engagement. In Sub-Saharan Africa, however, knowledge scarcity is one of the main challenges facing universities (Abrahams et al., 2007). This is despite the fact that new knowledge is built on existing knowledge, which must be accessible to those involved in the creation of new knowledge (i.e. flowing from where it is produced to where it is needed). This is manifested by the scarcity of knowledge transmission channels on the African continent, especially when comparison is drawn with Europe, America, and Asia. From 26 African countries, for instance, African Journals Online (AJOL) enumerates 353 journals. Indeed, several studies (e.g. Fullard, 2009) show that the creation, distribution and utilization of knowledge in Africa are still low. African researchers produce only $1.8 \%$ of the world's total scholarly publications, according to an article in the journal of Scientometrics on the state of science and technology across the continent.

According to Altbach (2007), this is due to: difficulties in distributing scholarly knowledge because of small markets that are often dispersed over wide geographical areas; low intellectual literacy rates to utilize available knowledge; language problems due to multiple tribes each with their own language dialects; dependency on the industrialized countries for knowledge creation and distribution; and deliberate policies of industrialized nations to maintain their power. Indeed, according to the AJOL site, AJOL was started to address difficulties of accessing African-published 
research papers which were under-utilized, under-valued and under-cited in the international and African research arenas. Although the Internet is a good way to change this, many hundreds of worthy, peer-reviewed scholarly journals published from Africa cannot host their content online in isolation because of resource limitations and the digital divide (Agaba, Kigongo-Bukenya and Nyumba, 2004). Valuable information has not reached the people who need it. At the same time as online academic resources from the developed Global North are made available to Africa (such as HINARI, AGORA and OARE), there needs to be corresponding online availability of information from Africa. AJOL was developed so that African countries could collectively play a greater role in the global online scholarly environment. Furthermore, African researchers also needed access to their own continent's scholarly publications.

Knowledge visibility: On the surface, the problems above seem to justify the existence of a scarcity of knowledge in Africa. Yet, as Kasozi (2009) argued, in this digital age, higher education is the necessary tool for the generation, storage and retrieval of knowledge for development. Kasozi (quoting Economist, 4 October 1997:S3) goes on to say that universities are the factories where knowledge is created and skilled workers manufactured. Unless universities in Africa with their mandate of teaching, carrying out research, and community engagements to solve societal problems are not playing their roles, the numerous graduates at the highest levels provide proof that knowledge is indeed being produced. The numerous theses and dissertations, produced before degree awards in universities, research reports and varying local and international donor support to research activities are all evidence of knowledge production. Altbach (2002) in Kasozi (2009) talks of how most of the information African universities use is produced elsewhere and is not often fresh, thereby contributing to a lack of higher-quality and ground-breaking knowledge being delivered in African universities. This affects the quality of knowledge produced in African universities.

Unfortunately, little is publicly available to show the existence of such works in internationally known access channels (especially web based). We believe there is a lot of knowledge out there created from research and other efforts in Africa. What is lacking in Africa is an effective distribution method to make this knowledge visible to the wider society. Instead, most of the knowledge in Africa is stored away in record offices or scattered in (closed) library collections.

The Association of African Universities (AAU)'s efforts of building a knowledge base, DATAD (Database of African Theses and Dissertations) seem to be experiencing the same fate as that of AJOL because of its limitation on abstract, as well as the high costs in subscription. To reverse the visibility challenge, Mohrman, Ma and Baker (2007) believe that universities and their staff need to think further than the acquisition and development of new knowledge to pay attention to the transmission of this knowledge and the challenges of technological innovation so as to carry their innovations through to completion. In short, created knowledge needs to be easily distributed to those who need it. 


\subsection{AHERO - A Contribution towards the Solution}

It is out of the scarcity and visibility challenges that the need for innovative approaches, through which academics in Africa can access quality information resources and disseminate their own research findings arises. AHERO was developed to create a knowledge base that brings together research information on higher education in Africa. AHERO is managed from the Centre for the Study of Higher Education (CSHE) at the University of Western Cape in South Africa together with the East African Institute of Higher Education Studies and Development (EAIHESD) at Makerere University in Uganda.

The AHERO project is one of over 900 interoperable open access archives. It is an international disciplinary repository for research texts that focus on the practice and development of higher education in Africa. Researchers upload their documents to AHERO through a semi-automated process. For the most part, this is intended as a supplementary, post-publication exercise to enhance the visibility of research articles, although conference papers, research reports, policy documents and theses may also be submitted. AHERO editors vet submissions for relevance, scholarly evidence and coherence, but do not otherwise practice editorial peer review.

\section{Methods Used to Develop AHERO}

The archive was developed in phases, first by staff at the CSHE, University of Western Cape, who currently host the website at http://ahero.uwc.ac.za . The first task was to identify experts in the field, to obtain their permission to include their work in the online archive and to either digitize or obtain an electronic file of such content. The Centre for Research on Science and Technology (CREST) at the University of Stellenbosch, Cape Town, was commissioned to undertake a search and a database of 1200 individuals who had published books, chapters, journal articles, conference and other occasional papers or research reports about African higher education in the past decade was supplied to the AHERO Project Team. This database served as a constructive instrument for the AHERO Team at CSHE, providing a starting point from which the search for current contact details for scholars began. Thereafter the team began contacting the researchers and informing them about the AHERO project. From the second year of the project in 2007, a project partner based at the EAIHESD, Makerere University in Uganda joined to aid the project with the identification of research information in the East African region and coordinate other project related activities. Currently, the team includes 3 administrators, whose duties include that of identification of suitable research documents and seeking permission from copyrights owners. Two assistants help with the digitization of documents that are submitted in hardcopy.

\section{Experiences}

Besides the subjective qualitative responses that can be offered through our direct daily experience, all correspondence and encounters with prospective authors and publishers was captured in a database. In this way we are able to run queries to 
discover exact measures with regard to the number of authors contacted, successful deposits in the archive, the types of formats represented, author and publisher responses and the number of embargoed papers. An additional source of information is the responses we have received from presenting the project at a number of conferences and workshops. Following close to three years' experience of administering AHERO an evaluative survey was initiated in March 2009. Different questionnaires were sent to two distinct groups, namely, contributing authors, and identified users. The results of the survey are presented in the next subsection.

\section{Survey Findings and Interpretations}

At a very basic level, it is possible to gauge that we were moderately successful in engaging researchers' receptivity towards open access. Out of 661 overtures to authors, positive responses were achieved from $53 \%$ of these (i.e., the number of authors in AHERO). To date (2009) the archive holds 448 papers; however, it is worth mentioning that it may take weeks or even months before consent is secured from authors, publishers or commissioning bodies. They may only reply after the second or even third reminder. Therefore, securing permission and populating the archive is an iterative and time-consuming process.

It is also noteworthy that only 73 out of 350 authors have self-archived their papers. In all other cases, the resources have been deposited by proxy by project staff. In response to our invitation, authors attach their files to an email, relying on the AHERO team to deposit on their behalf. From the evaluative survey we conducted, it transpires that, for many, this is due to lack of confidence with computers. Furthermore, although an open invitation to contribute papers appears on the AHERO homepage, virtually no one will initiate or spontaneously deposit a paper.

Copyright and open access: It is possible that authors continue to feel uncertain about their right to self-archive, particularly where they have assigned copyright to a publisher. In such cases, it is necessary to consult the publisher's policy with regard to self-archiving. The British SHERPA-ROMEO project has created an online searchable directory that provides a comprehensive record of publishers' copyright conditions as they relate to authors archiving their work on-line. It is interesting to note that although major publishers such as Elsevier will permit authors to selfarchive in an institutional repository; this freedom is not extended to a disciplinary repository. However, several publishers will allow the author's version of the post peer-reviewed article to appear on a non-profit site. Besides journal articles, we were also in direct liaison with publishers for permission to digitize chapters of books or papers from conference proceedings. Our experience has shown that book publishers, in comparison to the journal publisher would more readily concede to the use of a particular chapter in AHERO.

Where a publisher will not permit a journal article to be reproduced in the AHERO archive, we would embargo the full text but provide on-site functionality for users to request the full text from the author. The usage of this functionality is reported below. Only 37 papers in AHERO are embargoed where we have been unsuccessful in obtaining the author's post print consent.

Notwithstanding the difficulties associated with copyright and permissions, another sign of the growth in author awareness of the potential of open access is that the 
archive is growing steadily with a substantial number of monthly deposits. AHERO also accepts unpublished materials such as, research papers and institutional research. Since authors are the major copyright holders of these types of documents, they are approached for consent. However, the AHERO administrator checks with conference organizers as to the conditions under which conference papers were presented. It may be necessary for permission to be secured from such persons. Alternatively, where papers have been made available via a Creative Commons License, it is not mandatory to obtain permission first before using the research. However, the AHERO administrator courteously informs the author that their paper(s) have been deposited in the archive, when contacts are available.

How do authors respond to invitations to self-archive and share their research findings? Participants to our evaluative online survey were from 26 different countries with Uganda, South Africa and Kenya furnishing most respondents. The study has informed us about possible improvements, authors and users' overall impression of the archive, usage and frequency of visits. The author survey provides a variety of significant information about their research practices. The majority $(72 \%)$ of respondents were aware that their papers are housed in the archive. The following conclusions could be drawn: (a) Authors are generally satisfied with the database records in AHERO associated with their research. Ninety percent of author respondents have expressed acceptance and approval (b) All the authors expressed a willingness to contribute their research in the future.

Enhancing the Visibility and Usage of Africa-based research: AHERO aims to promote the communication of scholarship as the developing world remains at a disadvantage in terms of both the production and distribution of knowledge. The key to both of these is the functionality and performance of the AHERO platform. Because it is built according to the Open Archives Initiative (OAI) standards, AHERO is registered with OAIster, and OpenDOAR and EIFL services. This means that the records in the archive are automatically harvested by other service providers and are also crawled and indexed by major search engines like Google and Yahoo. In this way, papers deposited in AHERO are more readily discovered and used by a global readership. Respondents to our user survey were specifically asked how they had first discovered the archive and 50\% (15) answered that this transpired by using a search engine such as Google. The remaining users were either guided by a friend or colleague or were introduced to AHERO while visiting the CSHE or EAIHESD where the project team members are based. The metadata that is assigned to each record also contributes to the overall discoverability of the individual papers in the archive. For example, we enhance the discoverability of the archive by assigning both broad subject themes as well as indexing each item in the archive with a set of descriptive keywords. Users may thus navigate amongst papers in the archive by country, by author, by theme or by keyword descriptors.

Through the posting of documents online and the creation of additional access points, the individual papers become more visible. With this increased visibility comes a responsibility to ensure that the papers in the archive are of a high standard. Items that have already been peer-reviewed, as part of a publication process, are clearly marked with this status. Although the AHERO team does not conduct any form of expert peer review, each paper is vetted and reviewed to ensure that a 
scholarly method has been employed and that it makes an original and useful contribution to AHERO. Furthermore, AHERO provides additional services that we believe serve to facilitate visibility and usage of the papers in the archive. These include the possibility of registering to receive email alerts of newly-deposited papers that coincide with specific research interests and the ability to email the full-text of a paper to a 3rd party.

To what extent has AHERO content been broadcast and liberated? Currently, statistics indicate that there have been approximately 25,000 visits to our site and $28 \%$ of these visits result in the downloading of files. File downloads are now experienced at a rate of between 50 to 100 each week. More particularly, we are encouraged that visits are recorded from several regions across Africa. To date, AHERO has been visited by users from 27 African countries. It has to be acknowledged that, owing to inadequate infrastructure in Africa, most African Internet traffic is routed through America, making it difficult to accurately track the destination of the downloads from AHERO. Notwithstanding the opacity of some data, where AHERO indicates direct visits from named African countries, we are able to determine a $71 \%$ download rate. This is a significant finding, showing that AHERO resources are indeed needed.

Our survey results indicate that $27 \%$ of all users and authors replied that they would visit AHERO on a regular basis. $28 \%$ visits occasionally; $22 \%$ accesses the site monthly and $23 \%$ have only visited once.

Who is using the site? Because of the way that Internet traffic is routed, with most African visits routed through aol.com (USA), it is difficult to accurately pinpoint where the files are being downloaded. Although visits have been registered from 153 countries worldwide, judging from the e-print requests received, most of the visits are from South Africa and Africa in general. Approximately 3 e-print requests are processed each week. By the end November 2008, close to 269 e-print requests had been received, and processed, from the areas shown in Figure 1.

We believe that through satisfying these e-print requests, AHERO is genuinely able to liberate embargoed texts.

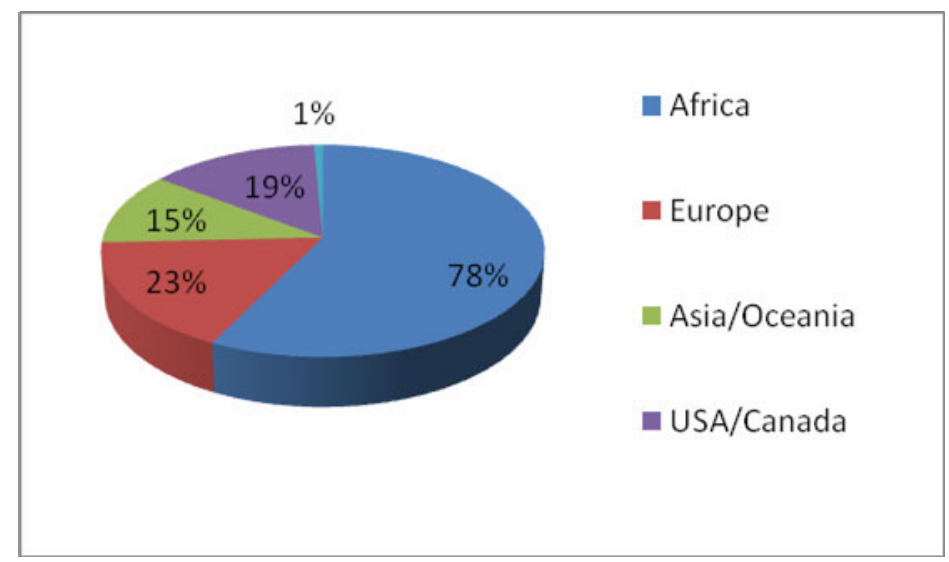

Fig. 1. Origin of E-print Requests 


\section{Conclusions and Recommendations}

The results from the survey and user statistics support the conclusion that AHERO is delivering relevant content to African scholars. Furthermore, the analysis of the online survey is based on a relatively small sample of Africans who, by their very participation in the survey, show an active interest in open access. This is also underscored by the many positive and unsolicited emails we receive which convey much enthusiasm for the project. It can be deduced that our survey sample is a privileged one, yet it is clear that authors who have contributed material to the archive are satisfied with its display and usage. The challenge that remains is one of evolving AHERO into a self-sustaining digital library. Authors should spontaneously self-archive their research, rather than rely on mediated deposit and invitations. Feedback from the questionnaire and our statistics inform us that more advocacy is needed, to alleviate this challenge. Increased contribution from authors and stakeholder support for open access is essential for the growth of the archive. The experience of AHERO may provide a useful starting point for other disciplinary communities that wish to consolidate and optimize their scholarship through an open access approach. From the viewpoint of the progress being made in the mainstreaming of open access elsewhere, the authors are optimistic that open access strategies and initiatives will be placed on the agenda of local research funders and research committees, so that it achieves more recognition for the benefits that it brings to the community. Lastly, AHERO's scope is limited to higher education; this means that other disciplines should follow its example to increase their visibility so that the wider society can access them.

\section{References}

1. Abrahams, L., Burke, M., Gray, E., Rens, A.: Opening access to knowledge in Southern African Universities. Study Series for the Southern African Regional Universities Association (SARUA), http: / /www. sarua.org/files/publications / OpeningAccess / Opening_Access_Knowledge_2008.pdf

2. Agaba, D.M., Kigongo-Bukenya, I.M.N., Nyumba, J.B.: Utilization of electronic information resources by academic staff at Makerere University. University of Dares Salaam Library Journal 6(1), 18-28 (2004)

3. AJOL, http://ajol.info/

4. Altbach, P.G.: The knowledge context: comparative perspectives on the distribution of knowledge. State University of New York, New York (2007)

5. Datonye, A.D.: The impact of the open access movement on medical based scholarly publishing in Nigeria (2008)

6. Fullard, A.: South African responses to open access publishing: a survey of the research community. South African Journal of Library and Information Science 73(1) (2007)

7. Kasozi, A.B.K.: Financing Uganda's Public Universities. Fountain Publishers, Kampala (2009) 
8. Mohamed, S.: African Higher Education Research Online (AHERO): A model for sustainable academic research and development. Paper Presented at the AAU 12th General Conference on the Role of Higher Education in Sustainable Development Held in Abuja, Nigeria (2009)

9. Mohrman, K., Ma, W., Baker, D.: The emerging global model of the research university. In: Philip, G.A., Patti, M.P. (eds.) Higher Education in the New Century: Global Challenges and Innovative Ideas. Boston College Center for International Higher Education, Boston (2007)

10. Möller, A.: The rise of open access journals: their visibility, and their prospects for the African scholarly community. Paper Presented at The Codesria Conference on Electronic Publishing and Dissemination, September 1-2, Dakar, Senegal (2004) 